\title{
Women in Academic Family Medicine
}

Jennifer Lochner, MD; Valerie Gilchrist, MD

(Fam Med. 2021;53(2):89-91.)

doi: 10.22454/FamMed.2021.717745

$\mathbf{W}$ omen are listed as authors in scientific and medical journal publications less often than men. This includes peer-reviewed publications across both specialty and general medical journals, ${ }^{1}$ case reports, ${ }^{2}$ and commentaries, ${ }^{3,4}$ and articles written by women are cited less often after publication. ${ }^{5}$ A recent series of papers shows this also is true in the family medicine literature including publications from the Robert Graham Center, ${ }^{6}$ the Annals of Family Medicine, the Journal of the American Board of Family Medicine, and Family Medicine. ${ }^{7,8}$

In this issue of Family Medicine, Mieses Malchuk and colleagues demonstrate two important findings in their review of the gender (by name) of authors in Family Medicine, the Annals of Family Medicine and the Journal of the American Board of Family Medicine between 2008 and 2017. First, over the study period, there were fewer female than male first and last authors. Second, there was a higher share of female first authors with female last authors. ${ }^{8}$ While the last author position may not necessarily indicate a senior author role $^{9}$ and a senior author may or may not be a mentor to the first author, they propose that women may be disproportionately mentored by other women. This is a potentially important and interesting observation, but mentorship means much more than just support for publication. ${ }^{10}$

Mentorship, often defined as a sharing of knowledge and expertise in a given area, may also include psychosocial support and guidance as mentees work toward career goals. Some mentors may also act as coaches or sponsors. A coach focuses on assisting faculty in skill development while a sponsor seeks to increase the visibility of faculty members and assists with identifying specific opportunities for career advancement. Mentees are often best served by multiple mentors, offering expertise in different areas, rather than a single mentor. ${ }^{10}$

Mentorship has been proposed as a strategy to address gender disparities and bias in academic medicine by assisting women faculty in navigating the promotion process. Yet in a 2016 report, $34 \%$ of female faculty at 13 medical schools did not currently have a mentor and $13 \%$ had never had a mentor. ${ }^{11} \mathrm{~A}$ recent systematic review analyzed mentorship programs for women in academic medicine at 19 US institutions. While the programs were diverse in their approaches, common components included paired or group mentoring, workshops, skills development, networking events, and journal or book discussion. These programs were generally highly rated by participants. Eight of the 19 programs reported improvements in objective outcomes including recruitment, retention, promotion and/or scholarly publications. ${ }^{12}$

In spite of programs to support women's retention and promotion, recent studies and reviews find that women persistently lag behind their male colleagues in promotions and appointment to leadership positions. One might assume this would improve over time, but several studies suggest otherwise. A study following a cohort of faculty from the 1995 National Faculty Survey through 17 years showed persistent gender disparities in rank, retention, and leadership positions. ${ }^{13}$ In addition, an examination of US allopathic medical school

From the Department of Family Medicine and Community Health, University of Wisconsin, Madison, WI 
graduates from 1979-2013, and faculty data through 2018, found women were less likely to be promoted to associate or full professor or appointed to department chair. These gaps did not narrow over the 35 years of the study and are more pronounced for women of underrepresented minority groups in medicine (URiM), an example of the combined burden of race and gender. ${ }^{13-15}$ The 2019 American Association of Medical Colleges report, The State of Women in Academic Medicine 2018-2019, found that women make up a minority of full professors (25\%), department chairs (18\% overall, $30.4 \%$ in departments of family medicine) and deans (18\%). This is notwithstanding the fact that the since 2003 women have made up about $50 \%$ of allopathic medical school matriculates. ${ }^{16}$

Why might this be? Women report not pursuing leadership positions in medicine because "leadership costs outweigh the benefits."17 Women experience gender-based discrimination, ${ }^{18}$ sexual harassment, ${ }^{19,20}$ and maternal discrimination. ${ }^{21}$ Gender stereotypes influence peer review of grants. ${ }^{22}$ Microaggressions and role challenges with lack of work-life balance contaminate many working environments. ${ }^{23,24}$ Women carry more responsibility than their male counterparts for personal and family life. ${ }^{25}$ Controlling for specialty, women physicians continue to be underpaid compared to men $^{26,27}$ and burnout for women continues to be more prevalent. ${ }^{28,29}$ The Association of American Medical Colleges reports that a staggering $41 \%$ of full-time women faculty left their position in academic medicine in $2018 .{ }^{16}$ Systemic implicit bias pervades medicine as it does our entire society. ${ }^{30-32}$

What are some solutions for women to be able to pursue any career path in academic medicine? We can start with collecting and assessing data on gender (and race and ethnicity) as it relates to authorship, salaries, promotion, and harassment, paying close attention to intersectionality, defined as "interconnected nature of social categorizations such as race, class, and gender creating overlapping and interdependent systems of discrimination or disadvantage." ${ }^{33}$ For women, and those who are members of URiM groups, to be "seen, heard, and valued" requires us to eliminate the "culture of exclusion." ${ }^{34}$ Carnes recommends treating unintentional or implicit bias as a "remediable habit" that may first be changed by becoming more aware of individual and collective biases, understanding their consequences, and learning skills to address them such as stereotype replacement, counter-stereotypic imaging, individuation, perspective taking, and increasing contact. ${ }^{35,36}$ Interventions are most effective when not limited to one focus but rather coordinated across the individual, interpersonal, institutional, professional, and policy levels. ${ }^{31,37}$ Examples of these might include policies to deal with discriminatory patient behavior, ${ }^{38,39}$ and the normalization of parenting within career expectations. ${ }^{40,41}$ Challenging accepted assumptions and norms by making part-time training during residency more accessible and loosening strict promotion clocks $^{42}$ is difficult yet necessary.

Mieses Malchuk and colleagues have added new insights to those of other authors in exposing bias in medicine, this time in family medicine. Family medicine is well positioned to respond because family physicians understand systems, social determinants of health, and advocacy. With women in nearly one-third of family medicine department chair roles, we have more role models than many specialties. To achieve greater equity and inclusion in family medicine, we must intentionally create and support diverse and welcoming pathways to professional achievement. The entrenched issues of systemic and structural patriarchy and racism within medicine require our attention. As novelist and thinker Chimamanda Ngozi Adichie states, "Culture does not make people. People make culture. If it is true that the full humanity of women is not our culture, then we can and must make it our culture." ${ }^{43}$

\section{References}

1. Hart KL, Perlis RH. Trends in proportion of women as authors of medical journal articles, 2008-2018. JAMA Intern Med. 2019;179(9):1285-1287. doi:10.1001/jamainternmed.2019.0907

2. Hsiehchen D, Hsieh A, Espinoza M. Prevalence of female authors in case reports published in the medical literature. JAMA Netw Open. 2019;2(5):e195000. doi:10.1001/jamanetworkopen.2019.5000

3. Mamtani M, Shofer F, Mudan A, et al. Quantifying gender disparity in physician authorship among commentary articles in three high-impact medical journals: an observational study. BMJ Open. 2020;10(2):e034056. doi:10.1136/ bmjopen-2019-034056

4. Thomas EG, Jayabalasingham B, Collins T, Geertzen J, Bui C, Dominici F. Gender disparities in invited commentary authorship in 2459 medical journals. JAMA Netw Open. 2019;2(10):e1913682. doi:10.1001/jamanetworkopen.2019.13682

5. Lerchenmueller MJ, Sorenson O, Jena AB. Gender differences in how scientists present the importance of their research: observational study. BMJ. 2019;367:16573.

6. Wilkinson E, Coffman M, Huffstetler A, Bazemore A, Jabbarpour Y. Trends in the gender ratio of authorship at the Robert Graham Center. Ann Fam Med. 2020;18(4):341-344. doi:10.1370/afm.2552

7. Jabbarpour Y, Wilkinson E, Coffman M, Mieses A. Has female authorship in family medicine research evolved over time? Ann Fam Med. 2020;18(6):496-502. doi:10.1370/ $\operatorname{afm} .2584$ 
8. Malchuk M, Coffman M, Wilkinson E, et al. Gender concordance of first and senior authors in family medicine journals. Fam Med. 2021;53(2):92-97.

9. Mavis B, Durning SJ, Uijtdehaage S. Authorship order in medical education publications: in search of practical guidance for the community. Teach Learn Med. 2019;31(3):288 297. doi:10.1080/10401334.2018.1533836

10. Coe C, Piggott C, Davis A, et al. Leadership pathways in academic family medicine: focus on underrepresented minorities and women. Fam Med. 2020;52(2):104-111. doi:10.22454/ FamMed.2020.545847

11. Carapinha R, Ortiz-Walters R, McCracken CM, Hill EV, Reede JY. Variability in women faculty's preferences regarding mentor similarity: A multi-institution study in academic medicine. Acad Med. 2016;91(8):1108-1118.

12. Farkas AH, Bonifacino E, Turner R, Tilstra SA, Corbelli JA Mentorship of women in academic medicine: A systematic review. J Gen Intern Med. 2019;34(7):1322-1329.

13. Carr PL, Raj A, Kaplan SE, Terrin N, Breeze JL, Freund KM. Gender differences in academic medicine: Retention, rank, and leadership comparisons from the National Faculty Survey. Acad Med. 2018;93(11):1694-1699.

14. Richter KP, Clark L, Wick JA, et al. Women physicians and promotion in academic medicine. N Engl $\mathrm{J}$ Med. 2020;383(22):2148-2157.

15. Roberts LW. Women and academic medicine, 2020. Acad Med 2020;95(10):1459-1464.

16. Lautenberger DM, Dandar VM. The state of women in academic medicine 2018-2019: Exploring pathways to equity. Washington, DC: Association of American Medical Colleges. 2020 https://store.aamc.org/downloadable/download/ sample/sample_id/330. Accessed January 11, 2021.

17. Roth VR, Theriault A, Clement C, Worthington J. Women physicians as healthcare leaders: a qualitative study. J Health Organ Manag. 2016;30(4):648-665.

18. Carr PL, Ash AS, Friedman RH, et al. Faculty perceptions of gender discrimination and sexual harassment in academic medicine. Ann Intern Med. 2000;132(11):889-896.

19. Jagsi R. Sexual harassment in medicine-\#MeToo. N Engl J Med. 2018;378(3):209-211. doi:10.1056/NEJMp1715962

20. Vargas EA, Brassel ST, Cortina LM, Settles IH, Johnson TRB, Jagsi R. \#MedToo: A large scale examination of the incidence and impact of sexual harassment of physicians and other faculty at an academic medical center. J Womens Health (Larchmt). 2020;29(1):13-20. doi:10.1089/ jwh.2019.7766

21. Adesoye T, Mangurian C, Choo EK, Girgis C, Sabry-Elnaggar H, Linos E; Physician Moms Group Study Group. Perceived discrimination experienced by physician mothers and desired workplace changes: A cross-sectional survey. JAMA Intern Med. 2017;177(7):1033-1036. doi:10.1001/jamainternmed.2017.1394

22. Magua W, Zhu X, Bhattacharya A, et al. Are female applicants disadvantaged in National Institutes of Health peer review? Combining algorithmic text mining and qualitative methods to detect evaluative differences in R01 reviewers' critiques. J Womens Health (Larchmt). 2017;26(5):560-570.

23. Hoff T, Scott S. The gendered realities and talent management imperatives of women physicians. Health Care Manage Rev. 2016;41(3):189-199. doi:10.1097/ HMR.0000000000000069

24. Barnes KL, McGuire L, Dunivan G, Sussman AL, McKee R. Gender bias experiences of female surgical trainees. J Surg Educ. 2019;76(6):e1-e14. doi:10.1016/j.jsurg.2019.07.024

25. Jolly S, Griffith KA, DeCastro R, Stewart A, Ubel P, Jagsi R. Gender differences in time spent on parenting and domestic responsibilities by high-achieving young physicianresearchers. Ann Intern Med. 2014;160(5):344-353.
26. Butkus R, Serchen J, Moyer DV, Bornstein SS, Hingle ST; Health and Public Policy Committee of the American College of Physicians. Achieving gender equity in physician compensation and career advancement: A position paper of the American College of Physicians. Ann Intern Med. 2018;168(10):721-723.

27. Pelley E, Carnes M. When a specialty becomes "women's work": trends in and implications of specialty gender segregation in medicine. Acad Med. 2020;95(10):1499-1506. doi:10.1097/ACM.0000000000003555

28. Rabatin J, Williams E, Baier Manwell L, Schwartz MD, Brown RL, Linzer M. Predictors and outcomes of burnout in primary care physicians. J Prim Care Community Health. 2016;7(1):41-43. doi:10.1177/2150131915607799

29. Chesak SS, Cutshall S, Anderson A, Pulos B, Moeschler S, Bhagra A. Burnout among women physicians: A call to action. Curr Cardiol Rep. 2020;22(7):45-54. doi:10.1007/ s11886-020-01300-6

30. Carnes M, Bartels CM, Kaatz A, Kolehmainen C. Why is John more likely to become department chair than Jennifer? Trans Am Clin Climatol Assoc. 2015;126:197-214.

31. Carr PL, Gunn C, Raj A, Kaplan S, Freund KM. Recruitment, promotion, and retention of women in academic medicine: how institutions are addressing gender disparities. Womens Health Issues. 2017;27(3):374-381. doi:10.1016/j. whi.2016.11.003

32. Girod S, Fassiotto M, Grewal D, et al. Reducing implicit gender leadership bias in academic medicine with an educational intervention. Acad Med. 2016;91(8):1143-1150. doi:10.1097/ACM.0000000000001099

33. Intersectionality. Dictionary.com. https://www.dictionary.com/ browse/intersectionality?s=tAccessed January 4, 2021.

34. Haggins AN. To be seen, heard, and valued: strategies to promote a sense of belonging for women and underrepresented in medicine physicians. Acad Med. 2020;95(10):1507-1510. doi:10.1097/ACM.0000000000003553

35. Carnes M, Devine PG, Baier Manwell L, et al. The effect of an intervention to break the gender bias habit for faculty at one institution: a cluster randomized, controlled trial. Acad Med. 2015;90(2):221-230. doi:10.1097/ACM.0000000000000552

36. Devine PG, Forscher PS, Cox WTL, Kaatz A, Sheridan J, Carnes M. A gender bias habit-breaking intervention led to increased hiring of female faculty in STEMM departments. J Exp Soc Psychol. 2017;73:211-215.

37. Cardel MI, Dhurandhar E, Yarar-Fisher C, et al. Turning chutes into ladders for women faculty: A review and roadmap for equity in academia. J Womens Health (Larchmt). 2020;29(5):721-733. doi:10.1089/jwh.2019.8027

38. Hu YY, Ellis RJ, Hewitt DB, et al. Discrimination, abuse, harassment, and burnout in surgical residency training. N Engl J Med. 2019;381(18):1741-1752. doi:10.1056/NEJMsa1903759

39. Morgan AU, Chaiyachati KH, Weissman GE, Liao JM. Eliminating gender-based bias in academic medicine: more than naming the "elephant in the room". J Gen Intern Med. 2018;33(6):966-968. doi:10.1007/s11606-018-4411-0

40. Rouse LP, Nagy-Agren S, Gebhard RE, Bernstein WK. Women physicians: gender and the medical workplace. J Womens Health (Larchmt). 2020;29(3):297-309. doi:10.1089/ jwh.2018.7290

41. Stack SW, Jagsi R, Biermann JS, et al. Childbearing decisions in residency: A multicenter survey of female residents. Acad Med. 2020;95(10):1550-1557.

42. Sklar DP. Women in medicine: enormous progress, stubborn challenges. Acad Med. 2016;91(8):1033-1035. doi:10.1097/ ACM.0000000000001259

43. Adichie CN. We All Should be Feminists. New York, NY: Anchor Books; 2014:16. 